\title{
Volatile Constituents of Floral Scents from Encyclia cordigera (Kunth) Dressler and E. randii (Barb. Rodr.) Porto \& Brade (Orchidaceae)
}

\author{
Franciléia M. de Vasconcelos, ${ }^{a}$ Eloisa Helena A. Andrade, ${ }^{a}$ Luiz Otávio A. Teixeira ${ }^{b}$ and \\ José Guilherme S. Maia ${ }^{\circledR *, a, c}$ \\ aPrograma de Pós-Graduação em Química, Universidade Federal do Pará, 66075-110 Belém-PA, Brazil \\ ${ }^{b}$ Associação dos Orquidófilos do Pará, Parque da Residência, 66063-240 Belém-PA, Brazil \\ 'Programa de Pós-Graduação em Química, Universidade Federal do Maranhão, 65085-580 São Luís-MA, Brazil
}

\begin{abstract}
Encyclia cordigera is native from Central America tropical region, and Encyclia randii occurs at Brazilian Amazon environment domains. Floral concentrates from both Encyclia species were extracted, analyzed by gas chromatography-mass spectrometry, and identified compounds belong to terpenoids, phenylpropanoids, and fatty acid derivatives classes. Primary constituents of the E. cordigera floral scent were $\beta$-ionol (45.4\%), terpinen-4-ol (12.4\%), benzyl benzoate (5.6\%), and indole (5.0\%). (2E,6Z)-Farnesol (24.9\%), heptanal (11.8\%), (E)-nerolidol (9.4\%), nonanal (6.4\%), p-vinyl-guaiacol (6.0\%), and phenylethyl benzoate (5.3\%) have predominated in the floral scent of $E$. randii. From the olfactory standpoint, E. cordigera scent was previously characterized as a blend of ionone-floral and aromatic-floral notes. Very likely, E. randii scent presents the woody fragrance due to sesquiterpenes $(2 E, 6 Z)$-farnesol and $(E)$-nerolidol and the fruity note from the aldehydes heptanal and nonanal. Floral perfume plays a fundamental role in attracting pollinating insects, whose symbiosis contributes to the appearance of chemical variations in orchid species.
\end{abstract}

Keywords: Orchidaceae, floral scents, $\beta$-ionol, $(2 E, 6 Z)$-farnesol, volatile concentrates

\section{Introduction}

Flowering plants and their volatile compounds attract birds, insects, and other animals, including mammals, as pollinators to their reproduction. More than 1,700 flower scent compounds, covering 990 taxa, have already been identified. ${ }^{1-5}$ The perianth is primarily responsible for scent emission, though all floral organs might contribute to the emission of scents. Floral scents are stored in the oil glands such as the trichomes before it is released into the air as volatile compounds. In addition to flowers, volatile compounds emitted by other plant organs are involved in its defense mechanisms. As seen, floral volatiles play a significant role in the plant's reproductive process by attracting pollinators, but they also can act as repellents ${ }^{6}$ and physiological protectors against abiotic stress. ${ }^{5}$

Floral volatiles are expected to be used in the composition of perfumes, cosmetics, flavors, and therapeutic applications. However, the volatiles emitted by flowers are also the main signals captured by insects

*e-mail: gmaia@ufpa.br

Editor handled this article: Paulo Cezar Vieira to select gratifying flower species associated with the respective flower colors. ${ }^{7}$ Floral scents are composed by different types of volatile compounds, usually lipophilic and of low molecular weight. Based on their origin, function, and biosynthesis, floral scents are grouped into three main classes of compounds: terpenoids, phenylpropanoids, and derivatives of fatty acids. In the species of Orchidaceae, these have been the main constituents. ${ }^{8}$

Orchidaceae is the most prominent flowering plant family, with ca. 736 genera and ca. 28,000 species, showing a wide diversity of epiphytic and terrestrial specimens, which colonizes almost every Earth habitat. ${ }^{9}$ Associated with the significant number of Orchidaceae species, there is also an extraordinary floral diversification spread in the world. Orchids are renowned for their abundance of morphological types, with an unending number of beautiful variations and very well represented in the monocotyledons' floral evolution. ${ }^{10}$

As epiphytic, terrestrial, or rupicolous herbs, with branching sympodial, ovoid pseudobulbs, resupinate flowers, a free lip or one partially adnate to the column, the genus Encyclia is composed of about 150 species, all neotropical, distributed from Florida to Northern Argentina 
and in West Indies, of which approximately 40 species occur in Brazil. In the Encyclia species, some variations have been observed for the same individual, and their floral diversity seems to be linked to pollination by food deception and mainly mediated by different bee types. Also, the genus is very diverse in the various seasonal environments, from where new species and natural hybrids have been continually reported. ${ }^{11-13}$

Encyclia cordigera (Kunth) Dressler (syn. Cymbidium cordigerum Kunth, Encyclia atropurpurea var. leucantha Schltr., E. atropurpurea var. rosea (Bateman) Summerh., E. cordigera var. rosea (Bateman) H.G. Jones, E. doeringii Hoehne, E. macrochila (Hook.) Neumann, Epidendrum atropurpureum var. roseum (Bateman) Rchb. f., E. cordigerum (Kunth) Foldats, among others) is native of the tropical and subtropical region of Central America and is currently cultivated as an ornamental plant in various parts of the world. In E. cordigera, the forms of its colors were not taken into account to establishing its synonymy. In the type variety of E. cordigera, the petals and sepals' predominant color is chocolate and the white lip. However, it is common to find plants with pink lips and chocolate sepals. $^{14,15}$

Encyclia randii (Barb. Rodr.) Porto \& Brade (syn. Epidendrum randii (L. Linden \& Rodigas) Barb. Rodr., Epidendrum atropurpureum var. randii (Barb. Rodr.) L. Linden \& Rodigas), an epiphyte with $65 \mathrm{~cm}$ tall, is characterized by ovoid-shaped pseudobulbs, almost always vinaceous, large and showy flowers, purple-green sepals and petals, entirely white lip with parallel pink stripes. It is distributed on the Amazonas, Pará, and Rondônia states, occurring at different Brazilian Amazon environment domains. ${ }^{16,17}$

Continuing the chemical-biological survey of the aromatic flora of the Brazilian Amazon, being carried out by our research group, this work aimed to extract the volatile concentrates of the flowers of Encyclia cordigera and $E$. randii, identify their chemical constituents, and associate them with other species/specimens previously analyzed and taxonomically close.

\section{Experimental}

\section{Plant materials}

The orchids Encyclia cordigera and E. randii (Figures 1a and $1 \mathrm{~b}$ ), which provided the botanical material for this work, are live plants cultivated in pots containing charcoal and wood shavings, existing in the private nursery of Mr Luiz Otávio Teixeira, located in the Amazon Garden Condominium, BR-316, km 6, 67015-795 Ananindeua, PA,
Brazil (coordinates: 1 22' 20.96" S/48 23' 34.14 W). A sample of $E$. randii, native to the Amazon region, is already deposited in the Goeldi Museum Herbarium (MG 205037), Belém, PA, Brazil, while waiting for the subsequent flowering of E. cordigera to deposit an exsiccate in the Goeldi Museum Herbarium. Encyclia cordigera has its origins in Central America. The flowers of E. cordigera and $E$. randii were collected at 6 am to extract their volatile constituents.

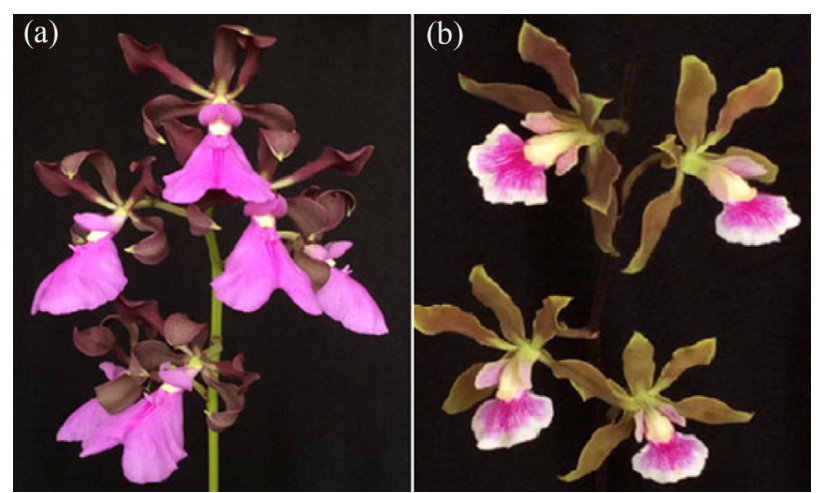

Figure 1. Floral morphology of studied species: Encyclia cordigera (a) and Encyclia randii (b).

\section{Obtaining and analyzing volatile concentrates}

The flowers of E. cordigera and E. randii, collected separately from the two specimens, were subjected to micro distillation-extraction in a Likens and Nickerson apparatus ( 3 flowers each, $15 \mathrm{~g}$ in total, $2 \mathrm{~h}$, duplicate) ${ }^{18}$ to obtain their volatile concentrates, using $n$-pentane $(99 \%$ high-performance liquid chromatography (HPLC) grade, $3 \mathrm{~mL}$ ) (Sigma-Aldrich, São Paulo, Brazil) as the solvent.

The volatile concentrates of Encyclia cordigera and E. randii were submitted to gas chromatography (GC) and gas chromatography-mass spectrometry (GC-MS) analysis. It was performed on a GCMS-QP2010 Ultra system (Shimadzu Corporation, Tokyo, Japan), equipped with an AOC-20i auto-injector and the GCMS-Solution software containing the Adams, ${ }^{19}$ NIST, ${ }^{20}$ and FFNSC-2 libraries. ${ }^{21}$ A Rxi-5ms (30 m $\times 0.25 \mathrm{~mm} ; 0.25 \mu \mathrm{m}$ film thickness) silica capillary column (Restek Corporation, Bellefonte, PA, USA) was used. The conditions of analysis were as follows: injector temperature: $250{ }^{\circ} \mathrm{C}$; oven temperature programming: $60-240{ }^{\circ} \mathrm{C}\left(3{ }^{\circ} \mathrm{C} \mathrm{min}^{-1}\right)$; helium as the carrier gas, adjusted to a linear velocity of $36.5 \mathrm{~cm} \mathrm{~s}^{-1}\left(1.0 \mathrm{~mL} \mathrm{~min}^{-1}\right)$; split mode injection (split ratio 1:20) of $1.0 \mu \mathrm{L}$ of the $n$-pentane solution; electron ionization at $70 \mathrm{eV}$; ionization source and transfer line temperatures of 200 and $250{ }^{\circ} \mathrm{C}$, respectively. The mass spectra were obtained by automatic scanning every $0.3 \mathrm{~s}$, with mass fragments in the range of $35-400 \mathrm{~m} / \mathrm{z}$. The retention index was calculated for all volatile components 
using a homologous series of C8-C40 n-alkanes (SigmaAldrich, Milwaukee, WI, USA) according to the linear equation of van den Dool and Kratz. ${ }^{22}$ Individual components were identified by comparing their retention indices and mass spectra (molecular mass and fragmentation pattern) with those existing in the GCMS-Solution system libraries. ${ }^{19-21}$ The quantitative data regarding the volatile constituents were obtained using a GC2010 series gas chromatograph, operated under similar conditions to those of the GC-MS system. The relative amounts of individual components were calculated by peak-area normalization using a flame ionization detector (GC-FID). Chromatographic analyses were performed in duplicate.

\section{Results and Discussion}

The chemical constituents of the flower volatile concentrates of Encyclia cordigera and E. randii, analyzed by GC and GC-MS, are listed in Table 1 . The yield of volatile concentrate was $0.2 \%$ for both orchids. In total, forty-four constituents were identified, comprising more than $99 \%$ of the volatile concentrates. Above $5 \%$, the primary components of the flowers of E. cordigera were $\beta$-ionol (45.4\%), terpinen-4-ol (12.4\%), benzyl benzoate $(5.6 \%)$, and indole $(5.0 \%)$ (Figure 2). Likewise, the constituents (2E,6Z)-farnesol (24.9\%), heptanal (11.8\%), (E)-nerolidol (9.4\%), nonanal (6.4\%), p-vinyl-guaiacol (6.0\%), linalool (5.5\%), phenylethyl benzoate (5.3\%), and phenylethyl alcohol $(5.0 \%)$ predominated in the volatile concentrate of $E$. randii (Figure 3).

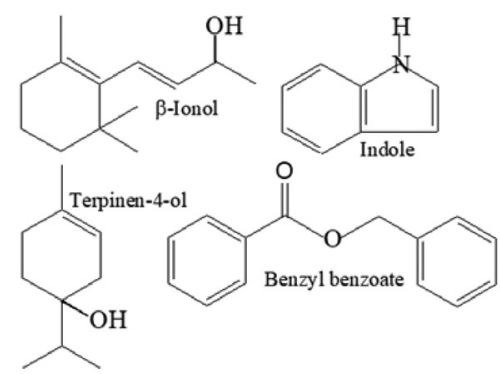

Figure 2. Primary constituents of volatile concentrate of E. cordigera.

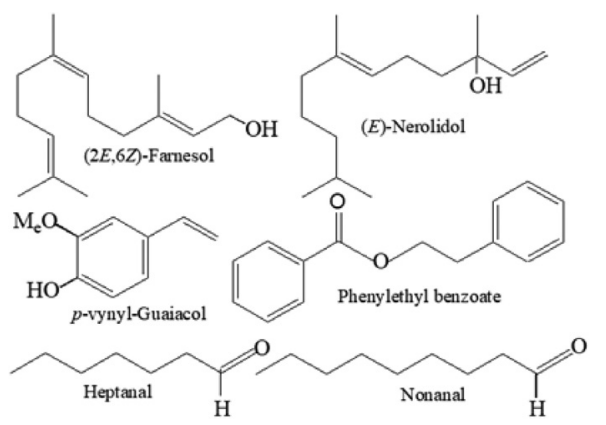

Figure 3. Primary constituents of volatile concentrate of E. randii.
Table 1. Constituents identified in the volatile concentrates of Encyclia cordigera and E. randii

\begin{tabular}{|c|c|c|c|c|}
\hline \multirow{2}{*}{ Compound } & \multirow{2}{*}{$\mathrm{RI}_{\text {Calc }}$} & \multirow{2}{*}{$\mathrm{RI}_{\text {Lit }}$} & \multicolumn{2}{|c|}{ Constituents / \% } \\
\hline & & & E. cordigera & E. randii \\
\hline 2-Methyl-3-pentanone & 745 & $742^{\mathrm{a}}$ & 3.5 & \\
\hline (2E)-Penten-1-al & 751 & $744^{\mathrm{b}}$ & 4.4 & \\
\hline 1-Pentanol & 756 & $759^{a}$ & 1.3 & \\
\hline 1-Hexen-3-ol & 784 & $778^{\mathrm{a}}$ & 0.2 & \\
\hline (3E)-Hexen-1-ol & 843 & $844^{\mathrm{b}}$ & & 3.0 \\
\hline (3Z)-Hexen-1-ol & 853 & $853^{\mathrm{a}}$ & & 0.9 \\
\hline 2,3-Heptanedione & 884 & $885^{\mathrm{a}}$ & & 0.7 \\
\hline Heptanal & 898 & $901^{\mathrm{b}}$ & 1.4 & 11.8 \\
\hline Benzaldehyde & 952 & $952^{\mathrm{b}}$ & 0.4 & \\
\hline trans-m-Mentha-2,8-diene & 978 & $979^{\mathrm{b}}$ & & 4.4 \\
\hline Benzene acetaldehyde & 1038 & $1036^{\mathrm{b}}$ & 0.4 & 2.8 \\
\hline$(E)-\beta$-Ocimene & 1047 & $1044^{\mathrm{b}}$ & 3.8 & \\
\hline$(2 E, 4 E)$-Hexadienol acetate & 1071 & $1070^{\mathrm{a}}$ & & 1.3 \\
\hline$p$-Cresol & 1075 & $1071^{\mathrm{b}}$ & & 2.6 \\
\hline Linalool & 1098 & $1095^{\mathrm{b}}$ & 0.2 & 5.5 \\
\hline Undecane & 1102 & $1100^{\mathrm{b}}$ & 0.2 & \\
\hline cis-Rose oxide & 1109 & $1106^{\mathrm{b}}$ & 1.9 & \\
\hline Nonanal & 1113 & $1107^{\mathrm{a}}$ & & 6.4 \\
\hline Phenylethyl alcohol & 1118 & $1113^{\mathrm{a}}$ & & 5.0 \\
\hline trans-Rose oxide & 1125 & $1122^{b}$ & 0.7 & \\
\hline Terpinen-4-ol & 1174 & $1174^{\mathrm{b}}$ & 12.4 & \\
\hline 2-Methoxy-p-cresol & 1184 & $1188^{b}$ & & 1.5 \\
\hline Methyl salicylate & 1190 & $1190^{\mathrm{b}}$ & 0.6 & \\
\hline Dodecane & 1196 & $1200^{b}$ & & 0.2 \\
\hline Indole & 1289 & $1290^{\mathrm{b}}$ & 5.0 & \\
\hline$(3 E-6 Z)$-Nonadienol acetate & 1300 & $1296^{\mathrm{a}}$ & & 0.5 \\
\hline Tridecane & 1308 & $1300^{\mathrm{b}}$ & & 0.4 \\
\hline$p$-Vinyl-guaiacol & 1316 & $1309^{b}$ & & 6.0 \\
\hline$\alpha$-Cubebene & 1339 & $1345^{\mathrm{b}}$ & 0.1 & \\
\hline$\alpha$-Longipinene & 1356 & $1350^{\mathrm{b}}$ & 2.6 & \\
\hline$(E)-\beta$-Damascenone & 1383 & $1383^{\mathrm{b}}$ & 0.3 & \\
\hline Tetradecane & 1408 & $1400^{\mathrm{b}}$ & & 0.4 \\
\hline Dodecanal & 1415 & $1408^{b}$ & & 0.4 \\
\hline$\beta$-Ionol & 1417 & $1412^{\mathrm{b}}$ & 45.4 & \\
\hline (E)-Caryophyllene & 1422 & $1417^{\mathrm{b}}$ & 2.3 & \\
\hline$(E)$ - $\beta$-Ionone & 1485 & $1487^{b}$ & 3.1 & \\
\hline$(E, E)$ - $\alpha$-Farnesene & 1508 & $1505^{\mathrm{b}}$ & 1.6 & \\
\hline$(E)$-Nerolidol & 1564 & $1561^{\mathrm{b}}$ & 1.7 & 9.4 \\
\hline cis- $\beta$-Elemenone & 1585 & $1589^{b}$ & & 4.6 \\
\hline Dillapiole & 1619 & $1620^{\mathrm{b}}$ & & 0.9 \\
\hline$(2 E, 6 Z)$-Farnesol & 1719 & $1716^{\mathrm{a}}$ & & 24.9 \\
\hline Benzyl benzoate & 1758 & $1759^{b}$ & 5.6 & \\
\hline Phenylethyl benzoate & 1864 & $1856^{\mathrm{a}}$ & & 5.3 \\
\hline$n$-Hexadecanol & 1881 & $1874^{\mathrm{b}}$ & & 0.8 \\
\hline $\begin{array}{l}\text { Terpenoids (monoterpenes and } \\
\text { sesquiterpenes) }\end{array}$ & & & 76.1 & 48.8 \\
\hline Fatty acid derivatives & & & 11.0 & 26.8 \\
\hline Phenylpropanoids/benzenoids & & & 12.0 & 24.1 \\
\hline Total / \% & & & 99.1 & 99.7 \\
\hline
\end{tabular}


From an olfactory point of view, Kaiser ${ }^{23}$ highlighted the "Encyclia perfume", characterized as a very diffuse "iononefloral" perfume, accompanied by distinct "aromatic floral" and "spicy floral" notes, that was exemplified by the analysis of smell from E. adenocarpa flowers, containing about 10\% $\beta$-ionone, together with a significant content of aliphatic and aromatic esters. As can be seen, the content of $\beta$-ionol and $\beta$-ionone is $48.5 \%$ in the volatile concentrate of the E. cordigera flowers. Although the chemical analysis does not substitute the olfactory evaluation, due to qualitative and quantitative variations that lead to distinct odors, it is assumed that the volatile concentrate of E. cordigera presents an "Encyclia perfume", as described by Kaiser $^{23}$ for the smell of E. adenocarpa (Lex.) Schltr. flowers, in association with the significant amounts of indole and benzyl benzoate present in the floral scents of both species. The volatile concentrate of the flowers of another specimen of E. cordigera, existing in Southeast Mexico, exhibited a different chemical composition, with cis-geraniol (nerol), benzyl benzoate, and indole as their primary constituents. ${ }^{24}$ In turn, the scent of $E$. randii presented a floral-woody note, probably due to the high amounts of the sesquiterpenes $(2 E, 6 Z)$-farnesol and $(E)$-nerolidol, associated with a fruity note from the aldehydes heptanal and nonanal, in a refreshing and pleasant combination. No previous analysis of the volatile composition of $E$. randii flowers has been found in the literature.

Some floral scents of other Encyclia species have been previously reported. Encyclia adenocarpa and E. parviflora from Mexico showed lightly fragrant flowers, with hexadecene, $(E)$-nerolidol, indole, and $(E)$ - $\beta$-ocimene as the more significant components in the volatile concentrate of the first species, and methyl 3,4,5-trimethoxybenzoate and $p$-vinylanisole in the volatile concentrate of the second species. ${ }^{24}$ The volatile constituents of the flowers of Encyclia vespa (Vell.) Dressler and E. fragrans (Sw.) Lemée, sampled in Belém, Brazil, were identified. Terpinen-4-ol, verbenone, trans-verbenol, and $\alpha$-pinene were the significant components of $E$. vespa flowers, while the compounds terpinen-4-ol, (2Z-6E)-farnesol and trans-verbenol have predominated in the $E$. fragrans flowers. ${ }^{25}$ The floral scent of another $E$. fragrans specimen, distributed from Mexico across Central and South America and West Indies, was also reported by Kaiser, ${ }^{23}$ where (E)- $\beta$-ocimene, 3,5-dimethoxy-toluene, $(E)$-methylcinnamate, hydroquinone dimethyl ether, and hexyl butyrate were the main constituents. The floral scents of three other Encyclia species were also described in the book by Kaiser. ${ }^{23}$ Encyclia baculus (Rchb. f.) Dressler \& G.E. Pollard, distributed from Mexico to Colombia, was rich in (E)- $\beta$-ocimene, 2,2,6-trimethyl-cyclohex-2-ene-1,4-dione, and benzaldehyde; Encyclia citrina (Lex.) Dressler, occurring in Mexico, was rich in ipsdienol, ipsdienone, myrcene, and geranial; and Encyclia glumacea (Lindl.) Pabst, existing in Brazil, was rich in linalool and $(E)-\beta$-ocimene.

To survive and reproduce, plants interact with various organisms in their environment to defend themselves against herbivores and pathogens and, for sexual reproduction, they need to attract insect pollinators. Therefore, the plants have evolved defense signals, such as herbivore-induced volatile signals and visual and olfactory floral signals, to attract pollinators. The floral scent stands out for its chemical variation between floral signals, both among and within taxa. ${ }^{26}$ In a complementary way, ${ }^{27}$ hypothesized that in the plant-pollinator relationship, floral scent plays a fundamental role in attracting pollinating insects, whose symbiosis contributes to the plant evolution, resulting in the appearance of intra- and interspecific variations which will be more related to the volatile composition of the floral scent than the proper floral morphology.

The floral chemical diversity mediates various functions to attract pollinators or deter herbivores from consuming the plant's reproductive structures. ${ }^{28}$ As already mentioned, more than 1700 constituents of the scent of flowers, at about 1000 taxa, have been reported. The floral scent comprises different secondary metabolism compounds in plants: terpenoids, phenylpropanoids, and fatty acid derivatives. ${ }^{5}$ Terpenes are produced by both the classical mevalonate and the methylerythritol phosphate pathways, ${ }^{29}$ and they represent the largest group of plant floral volatiles, including those emitted by orchids. Phenylpropanoids are the second most dominant group of volatile compounds in plant floral scents, produced from the aromatic amino acid phenylalanine via the shikimate pathway and some enzymatic steps. Among the volatile floral compounds, fatty acid derivatives are the smallest group, consisting mainly of floral fatty acids derived from $\mathrm{C} 18$ polyunsaturated fatty acids and linolenic and linoleic acids. ${ }^{30}$ In the floral scents of E. cordigera and E. randii, the terpenic compounds (monoand sesquiterpenes) were the major constituents (76.1 and $48.8 \%$ ), followed by benzenoids/phenylpropanoids (12.0 and $24.1 \%)$ and fatty acid derivatives (11.0 and 26.8\%), respectively.

The monoterpenes and sesquiterpenes, linalool, terpinen-4-ol, $(E)$ - $\beta$-ocimene, farnesene, $(E)$-nerolidol, farnesol, and $(E)$-caryophyllene, identified in the volatile concentrates of E. cordigera and E. randii, are common constituents found in other plant floral scents, particularly in orchids. ${ }^{3}$ The ionones originate from the oxidative cleavage of carotenoids, resulting in low molecular weight volatile compounds, ${ }^{31}$ such as $\beta$-ionol and $(E)$ - $\beta$-ionone found in the E. cordigera and E. randii floral scents. 
Lipoxygenases and hydroperoxide lyases are involved in the production of short-chain alcohols, aldehydes, and esters, ${ }^{32}$ such as 2-methyl-3-pentanone, (2E)-penten-1-ol, 1-pentanol, 1-hexen-3-ol, (3E)- and (3Z)-hexen-1-ol, heptanal, nonanal, $(3 E, 6 Z)$-nonadienol acetate, and dodecanal, all of them produced by the degradation of C-18 fatty acids and identified in the E. cordigera and E. randii volatile concentrates. Phenylpropanoids belong to another class highly distributed among aromatic flower compounds. More than 300 compounds of this class have been identified, which includes benzaldehyde, benzene acetaldehyde, $p$-vinyl-guaiacol, $p$-cresol, 2-methoxy$p$-cresol, phenylethyl alcohol, phenylethyl benzoate, benzyl benzoate, methyl salicylate, indole, and dillapiole, ${ }^{5}$ all of them found in the floral scents of E. cordigera and $E$. randii.

\section{Conclusions}

The floral scents of E. cordigera and $E$. randii exhibited volatile compounds from the classes of terpenoids, phenylpropanoids, and fatty acid derivatives. The main constituents of the floral scent of E. cordigera were $\beta$-ionol, terpinen-4-ol, benzyl benzoate, and indole, while $(2 E, 6 Z)$-farnesol, heptanal $(E)$-nerolidol, nonanal, and $p$-vinyl-guaiacol have predominated in the floral scent of $E$. randii. From the olfactory standpoint, the scent of E. cordigera can be characterized as a blend of ionone-floral and aromatic-floral notes. In contrast, the scent of $E$. randii presented a floral-woody note due to the sesquiterpenes $(2 E, 6 Z)$-farnesol and $(E)$-nerolidol with a fruity note from the aldehydes heptanal and nonanal, in a refreshing and pleasant combination. It has been considered that floral perfume plays a fundamental role in attracting pollinating insects, whose symbiosis contributes to the evolution of the plant and the appearance of specific variations related to floral perfume's volatile composition than floral morphology.

\section{Acknowledgments}

The authors are grateful to CNPq and CAPES, Brazilian government institutions, for scientific research support, contributing to the execution of aromatic and medicinal plants projects in the Amazon.

\section{References}

1. Knudsen, J. T.; Tollsten, L.; Bergstrom, G.; Phytochemistry 1993, 33, 253.

2. Pichersky, E.; Raguso, R. A.; Lewinsohn, M.; Croteau, R.; Plant Physiol. 1994, 106, 1533.
3. Dudareva, N.; Pichersky, E.; Plant Physiol. 2000, 122, 627.

4. Effmert, U.; Buss, D.; Rohrberk, D.; Piechulla, B. In Biology of Floral Scent; Dudareva, N.; Pichersky, E., eds.; CRC Press: Florida, 2006, p. 105.

5. Knudsen, J. T.; Eriksson, R.; Gershenzon, J.; Bot. Rev. 2006, $72,1$.

6. Kessler, D.; Gase, K.; Baldwin, I. T.; Science 2008, 321, 1200.

7. Delle-Vedore, R.; Juillet, N.; Bessière, J. M.; Grison, C.; Barthes, N.; Pailler, T.; Dormont, L.; Schatz, B.; Phytochemistry 2011, 72, 735.

8. Hsiao, Y.-Y.; Pan, Z.-J.; Hsu, C.-C.; Yang, Y.-P.; Hsu, Y.-C.; Chuang, Y.-C.; Shih, H.-H.; Chen, W.-H.; Tsai, W.-C.; Chen, H.-H.; Plant Cell Physiol. 2011, 52, 1467.

9. The Plant List 2014, theplantlist.org/1.1/browse/A/Orchidaceae, accessed in August 2021.

10. Chase, M. W.; Cameron, K. M.; Freudenstein, J. V.; Pridgeon, A. M.; Salazar, G.; Van Den Berg, C.; Schuiteman, A.; Bot. J. Linn. Soc. 2015, 177, 151.

11. Dressler, R. L.; Phylogeny and Classification of the Orchid Family; Dioscorides Press: Portland, 1993.

12. Van Den Berg, C.; Carnevali, G. In Genera Orchidacearum, v. 4; Pridgeon, A. M.; Cribb, P. J.; Chase, M. W.; Rasmussen, F. N., eds.; Oxford University Press: New York, 2005, p. 232.

13. Vale, A.; Pérez-Obregón, R. A.; Faife-Cabrera, M.; Álvarez, J. C.; Rojas, D.; Syst. Bot. 2014, 39, 1076.

14. The Plant List 2014, Encyclia cordigera (Kunth) Dressler, theplantlist.org/tpl1.1/record/kew-67028, accessed in August 2021.

15. Leopardi-Verde, C. L.; Carnevali, L.; Romero-González, G. A.; J. Syst. Evol. 2017, 55, 110.

16. The Brazil Flora Group (BFG); Rodriguésia 2015, 66, 1085.

17. Koch, A. K.; Miranda, J. C.; Hall, C. F.; Rodriguésia 2018, 69, 165.

18. Likens, S. T.; Nickerson, G. B.; Am. Soc. Brew. Chem. 1964, 22,5 .

19. Adams, R. P.; Identification of Essential Oil Components by Gas Chromatography/Mass Spectrometry, $4^{\text {th }}$ ed.; Allured Publishing Corporation: Carol Stream, Ilinois, 2007.

20. National Institute of Standards and Technology (NIST); Mass Spectral Library (NIST/EPA/NIH, v.2.0d); The NIST Mass Spectrometry Data Center, Gaithersburg, 2011.

21. Mondello, L.; FFNSC 2: Flavors and Fragrances of Natural and Synthetic Compounds, Mass Spectral Database; John Wiley \& Sons Inc.: New York, 2011.

22. van den Dool, H.; Kratz, P.; J. Chromatogr. A 1963, 11, 463.

23. Kaiser, R.; The Scent of Orchids: Olfactory and Chemical Investigations; Elsevier Science Publishers B. V.: Amsterdam, 1993.

24. Cancino, A. D. M.; Damon, A.; Lankesteriana 2006, 6, 83.

25. Zoghbi, M. G. B.; Andrade, E. H. A.; da Silva, M. F. F.; Maia, J. G. S.; Acta Amazonica 1992, 32, 65. 
26. Schiestl, F. P.; Ecol. Lett. 2010, 13, 643.

27. Bergström, G.; Birgersson, G.; Groth, I.; Nilsson, A.; Phytochemistry 1992, 31, 2315.

28. Wright, G. A.; Schiestl, F. O.; Funct. Ecol. 2009, 23, 841.

29. Oldfield, E.; Lin, F. Y.; Angew. Chem., Int. Ed. 2012, 51, 1124.

30. Dudareva, N.; Klempien, A.; Muhlemann, J. K.; Kaplan, I.; New Phytol. 2013, 198, 16.
31. Aloum, L.; Alefishat, E.; Adem, A.; Petroianu, G.; Molecules 2020, 25, 5822.

32. Schilling, B.; Kaiser, R.; Natsch, A.; Gautschi, M.; Chemoecology 2010, 20, 135 .

Submitted: June 4, 2021 Published online: September 9, 2021 